\title{
A study of the factors associated with non-traumatic intracerebral hemorrhage (ICH) in patients with chronic systemic hypertension
}

\author{
Mozhgan Taghizadeh', Mahdi Foroughian², Hamidreza Vakili , Seyed Reza Habibzadeh², Reza Boostani ${ }^{4}$, \\ Negar Morovatdar ${ }^{5}$, Ehsan Bolvardi ${ }^{*}$
}

'Department of Emergency Medicine, Mashhad University of Medical Sciences, Mashhad, Iran ${ }^{2}$ Department of Emergency Medicine, Faculty of Medicine, Mashhad University of Medical sciences, Mashhad, Iran ${ }^{3}$ Neuroscience Research Center, Baqiyatallah University of Medical Sciences, Tehran, Iran ${ }^{4}$ Department of Neurology, Faculty of Medicine, Mashhad University of Medical Sciences, Mashhad, Iran ${ }^{5}$ Clinical Research Unit, School of Medicine, Mashhad University of Medical Sciences, Mashhad, Iran

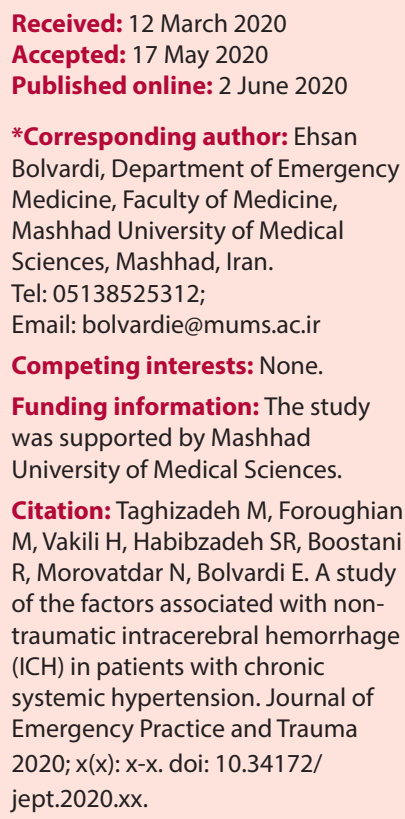

\begin{abstract}
Objective: Intracerebral hemorrhage $(\mathrm{ICH})$ following systemic and chronic hypertension is one of the main causes of acute stroke leading to disability and death. Identifying the risk factors in $\mathrm{ICH}$ patients can be effective in reducing bleeding and the rates of mortality and disability in these patients. This study was carried out to investigate the factors associated with $\mathrm{ICH}$.

Methods: A total of 134 patients with chronic systemic hypertension who had ICH were enrolled in this study. The amount of ICH was measured through computed tomography (CT scan). The subjects were divided into two groups of high $(>30 \mathrm{~mL})$ and low $(<30 \mathrm{~mL})$ $\mathrm{ICH}$ volume, and the related risk factors in the two groups were studied and compared using SPSS software version 21.

Results: The mean age of the subjects was 66.04 years, and 71 (52.99\%) individuals were females. The mean volume of ICH was $24.47 \mathrm{~mL}$, with $29.10 \%$ of the subjects (39 patients) having $>30 \mathrm{~mL}$ and $70.90 \%$ ( 95 patients) having $<30 \mathrm{~mL}$ of ICH. The results of studying ICHrelated factors in the multiple logistic regression showed that ischemic heart disease (IHD) (odds ratio $[O R]=2.243, P$ value $<0.05)$ and cardiovascular disease $(O R=3.294, P$ value $<0.05$ ) were the co-existing diseases that increased the odds of developing $\mathrm{ICH}$.

Conclusion: The results of this study showed that less than $30 \%$ of the subjects had high volumes of bleeding, and the co-existence of IHD was considered as a strong independent risk factor affecting the volume of $\mathrm{ICH}$ associated with worse prognosis.

Keywords: Blood pressure, Intracerebral hemorrhage, Stroke, Chronic systemic hypertension, patients
\end{abstract}

\section{Introduction}

Intracerebral hemorrhage $(\mathrm{ICH})$ due to hypertension is one of the most common causes of acute stroke leading to disability and death in adults in developing countries, accounting for about $10 \%$ to $20 \%$ of all strokes $(1,2)$. This type of hemorrhage occurs as a result of degenerative changes in the walls of cerebral arteries in the form of lipohyalinosis and generating false aneurysms and their rupture (3). Besides, polymorphisms that affect the structure or surface of platelet glycoproteins may contribute to the occurrence of primary ICH (4).

The most important causes of ICH include hypertension and risk factors such as anticoagulants, alcohol overuse, low-density lipoprotein (LDL) cholesterol, and high triglycerides (5). Unlike the developing countries, the incidence of $\mathrm{ICH}$ in developed countries has decreased dramatically with the improvement and control of blood pressure, so that ICH accounts for $8 \%-15 \%$ of strokes in Western countries and 30\%-40\% in Asian countries $(6,7)$. Clinical reports of the patients with $\mathrm{ICH}$ have shown that the mortality rates vary from $35 \%$ to $45 \%$ within 3 months of follow-up and $47 \%$ after a year (8). Bleeding volume is one of the most important independent factors affecting the prognosis of the patients with ICH (9) and it can determine the final outcome of the disease (10). Studies have shown that increased bleeding in people with $\mathrm{ICH}$ is associated with increased disability and mortality rates $(10,11)$. 
Identifying the risk factors affecting the prognosis of the patients with ICH can effectively reduce mortality and disability in these patients (10). Moreover, efficient management of the patients, especially those with poor prognosis, requires consideration of the factors such as age, blood glucose level, blood pressure, volume and location of bleeding, and consciousness. The present study aimed to evaluate the factors associated with ICH in patients with chronic systemic hypertension in order to implement effective therapies and interventions to reduce the rates of mortality and morbidity in these patients.

\section{Methods}

Prior to the initiation of the study, permission from the Ethics Committee (IR.MUMS.MEDICAL.REC.1397.685) was obtained and informed consent was granted from the participants. In this cross-sectional study, 134 patients with chronic systemic hypertension who had nontraumatic cerebral hemorrhage ( $\mathrm{ICH}$ ) and were admitted to the emergency department of Ghaem hospital in Mashhad entered into the study. The inclusion criteria encompassed: 1) being at least 15 years of age, 2) having chronic systemic hypertension and 3) evidence of bleeding in the brain tissue. The patients with aneurysms and brain tumors and those with arteriovenous malformations were excluded from the study. The amount of $\mathrm{ICH}$ was measured through computed tomography (CT scan) at admission to the emergency room. Based on their $\mathrm{ICH}$ volume, the subjects were divided into two groups of high $(>30 \mathrm{~mL})$ and low hemorrhage volume $(<30 \mathrm{~mL})$ using the Broderick's method (10).

Some study checklists $(10,12)$ were used to assess the risk factors for ICH incidence, including age, sex, duration of hypertension, multi-drug therapy, correct and continuous treatment, comorbidities, co-administration of anticoagulants, and coagulation and hematological disorders. The checklists were completed by the patients and their companions. The duration of hypertension, the type of treatment, and the number of drugs used were also thoroughly evaluated.

Descriptive statistics such as mean and standard deviation were used to describe the data. The $\chi^{2}$ and Fisher Exact tests were also used to examine the frequency distribution of ICH-related risk factors. Besides, the odds ratio (OR) and 95\% confidence interval (95\% CI) for ICH-related risk factors were calculated through univariate logistic regression. Finally, in order to eliminate the effect of confounding factors, the variables with a lower-than- 0.2 significance level in the univariate model were entered into the multivariate logistic regression. The statistical analysis was performed using the Stata software (StataCorp, College Station, Texas) version 12, and the significance level was considered lower than 0.05 .

\section{Results}

A total of 134 patients with ICH were included in this study with the mean age of $66.04 \pm 14.15$ years, of whom 71 (52.99\%) were females and $63(47.01 \%)$ were males. The mean ages of the male and female participants were 65.35 and 66.64 years, respectively. Examining the causes of ICH-patients' referral to the health center showed that they most commonly referred due to LOC (loss of consciousness) (28.91\%), left hemiparesis (16.41\%), and right hemiparesis (13.28\%). The mean of $\mathrm{ICH}$ volume was $24.47 \pm 20.12 \mathrm{~mL}$, and it was well found out that $29.10 \%$ of the subjects ( 39 ones) had greater than $30 \mathrm{~mL}$ of ICH and 70.90\% (95 subjects) had less than $30 \mathrm{~mL}$.

The results showed that there was not a significant relationship between the ICH volume and demographic as well as clinical variables such as gender, duration of hypertension, duration of hypertension treatment, regular visits to physicians, number of medications used, and frequent hospitalizations due to hypertension ( $P$ value $>$ 0.05) (Table 1).

Regarding ICH-associated diseases, we noticed that $43.75 \%$ of the ischemic heart disease (IHD) patients had an ICH greater than $30 \mathrm{~mL}$, while the rate was $24.5 \%$ in non-IHD patients, showing a significant difference between ICH and the prevalence of IHD $(P$ value $=0.03)$. No significant relationship was observed between other comorbidities and high ICH in the study subjects ( $P$ value $>0.05$ ) (Table 2).

The results of logistic regression between the ICH-related factors also showed that IHD increased the odds of hemorrhage with a volume greater than $30 \mathrm{~mL}$ by about 2.395 times compared to non-IHD individuals, which was statistically significant $(\mathrm{OR}=2.395, P$ value $=0.039)$. This indicated the role of IHD risk factor in increasing ICH. The results also showed that there was no significant relationship between ICH volume and other factors such as duration of having hypertension $(\mathrm{OR}=2.181, P$ value $=0.117)$, non-use of antihypertensive drugs $(\mathrm{OR}=0.878$, $P$ value $=0.750)$, lack of regular visits to physicians $(\mathrm{OR}=$ $1.756, P$ value $=0.264$ ), and other comorbidities (Table 3 ). The results of multiple logistic regression between the factors associated with ICH volume presented in Table 4 showed that developing IHD and cerebrovascular accident (CVA) increased the risk of ICH by controlling other confounding factors such as duration of having the disease and the subject's gender. That is to say, the patients with IHD had a higher chance of developing ICH by 2.24 times $(\mathrm{OR}=2.243, P$ value $=0.04)$. The people with CVA also had a higher chance of developing ICH by 3.29 times compared to non-CVA individuals $(\mathrm{OR}=3.294, P$ value $=0.028)$.

\section{Discussion}

The results of this study which was carried out to investigate the factors related to the $\mathrm{ICH}$ volume in patients with chronic systemic hypertension showed that the mean hemorrhage volume was $24.47 \pm 20.12 \mathrm{~mL}$, with about one third (29.10\%) of the subjects having high $\mathrm{ICH}$. 
Table 1. Relationship between ICH volume and demographic and clinical factors

\begin{tabular}{|c|c|c|c|c|}
\hline \multirow{2}{*}{ Variable } & & \multicolumn{2}{|c|}{ ICH volume } & \multirow{2}{*}{$P$ value } \\
\hline & & $\mathrm{ICH} \leq 30 \mathrm{~mL}$ & $\mathrm{ICH}>\mathbf{3 0} \mathrm{mL}$ & \\
\hline Age (year) & & $65.37 \pm 1.43$ & $67.68 \pm 2.54$ & 0.407 \\
\hline \multirow{2}{*}{ Gender } & Male & $41(65.08 \%)$ & $22(34.92 \%)$ & \multirow{2}{*}{0.185} \\
\hline & Female & $54(76.05 \%)$ & $17(23.95 \%)$ & \\
\hline \multirow{2}{*}{ Duration of having hypertension } & Less than 10 years & $80(72.73 \%)$ & $30(27.27 \%)$ & \multirow{2}{*}{0.120} \\
\hline & Over 10 years & $11(55 \%)$ & $9(45 \%)$ & \\
\hline \multirow{3}{*}{ Duration of drug therapy } & No treatment & $13(81.12 \%)$ & $3(18.88 \%)$ & \multirow{3}{*}{0.662} \\
\hline & Less than 5 years & 47 (69.11\%) & $21(30.89 \%)$ & \\
\hline & Over 5 years & $33(68.75 \%)$ & 15 (31.25\%) & \\
\hline \multirow{3}{*}{ Number of drugs used } & No drug & $9(90 \%)$ & $1(10 \%)$ & \multirow{3}{*}{0.279} \\
\hline & Single drug & 49 (66.21\%) & 25 (33.79\%) & \\
\hline & Multiple drugs & $36(73.47 \%)$ & $13(26.53 \%)$ & \\
\hline \multirow{2}{*}{ Use of anticoagulants } & Yes & $4(80 \%)$ & $1(20 \%)$ & \multirow{2}{*}{0.545} \\
\hline & No & $91(70.54 \%)$ & $38(29.46 \%)$ & \\
\hline \multirow{2}{*}{$\begin{array}{l}\text { Coagulopathy or hematological } \\
\text { disorder }\end{array}$} & Yes & $1(100 \%)$ & $0(0 \%)$ & \multirow{2}{*}{0.709} \\
\hline & No & $94(70.67 \%)$ & $39(29.33 \%)$ & \\
\hline \multirow{2}{*}{$\begin{array}{l}\text { Continuous use of antihypertensive } \\
\text { drugs }\end{array}$} & Yes & 29 (69.04\%) & 13 (30.96\%) & \multirow{2}{*}{0.831} \\
\hline & No & $66(71.74 \%)$ & $26(28.26 \%)$ & \\
\hline \multirow{2}{*}{ Regular visits to physicians } & Yes & $23(79.31 \%)$ & $6(20.69 \%)$ & \multirow{2}{*}{0.186} \\
\hline & No & 72 (68.57\%) & 33 (31.43\%) & \\
\hline \multirow{2}{*}{$\begin{array}{l}\text { Frequent hospitalization due to } \\
\text { hypertension }\end{array}$} & Yes & $4(100 \%)$ & $0(0 \%)$ & \multirow{2}{*}{0.248} \\
\hline & No & $91(70 \%)$ & 39 (30\%) & \\
\hline
\end{tabular}

Significance level: $<0.05$

Table 2. Relationship between ICH volume and underlying comorbidities

\begin{tabular}{|c|c|c|c|c|}
\hline \multirow[b]{2}{*}{ Variable } & & \multicolumn{2}{|c|}{ ICH volume } & \multirow[b]{2}{*}{$P$ value } \\
\hline & & $\mathrm{ICH}>\mathbf{3 0} \mathrm{mL}$ & $\mathrm{ICH} \leq 30 \mathrm{~mL}$ & \\
\hline \multirow{2}{*}{ IHD } & Yes & $18(56.25 \%)$ & $14(43.75 \%)$ & \multirow{2}{*}{$0.03^{*}$} \\
\hline & No & 77 (75.5\%) & $25(24.5 \%)$ & \\
\hline \multirow{2}{*}{ Diabetes mellitus } & Yes & $30(66.67 \%)$ & $15(33.33 \%)$ & \multirow{2}{*}{0.546} \\
\hline & No & $65(73.03 \%)$ & $24(26.97 \%)$ & \\
\hline \multirow{2}{*}{ Hyperlipoproteinemia } & Yes & $20(71.42 \%)$ & $8(28.58 \%)$ & \multirow{2}{*}{0.572} \\
\hline & No & 75 (70.75\%) & $31(29.25 \%)$ & \\
\hline \multirow{2}{*}{$\begin{array}{l}\text { Chronic obstructive pulmonary } \\
\text { disease }\end{array}$} & Yes & $1(100 \%)$ & $0(0 \%)$ & \multirow{2}{*}{0.709} \\
\hline & No & $94(70.67 \%)$ & 39 (29.33\%) & \\
\hline \multirow{2}{*}{ Congestive heart failure } & Yes & $2(100 \%)$ & $0(0 \%)$ & \multirow{2}{*}{0.501} \\
\hline & No & $93(70.45 \%)$ & $39(29.55 \%)$ & \\
\hline \multirow{2}{*}{ CVA } & Yes & $11(55 \%)$ & $9(45 \%)$ & \multirow{2}{*}{0.111} \\
\hline & No & $84(73.68 \%)$ & $30(26.32 \%)$ & \\
\hline \multirow{2}{*}{ Chronic kidney disease } & Yes & $2(66.67 \%)$ & $1(33.33 \%)$ & \multirow{2}{*}{0.647} \\
\hline & No & 93 (71\%) & $38(29 \%)$ & \\
\hline
\end{tabular}

Abbreviations: ICH, Intracerebral hemorrhage; IHD, ischemic heart disease; CVA, cerebrovascular accident.

It was also found that LOC, right hemiparesia and left hemiparesia were the most common causes of ICH.

The results of similar studies show that age and male gender were independent factors associated with $\mathrm{ICH}$ incidence and mortality $(10,13,14)$, but in our study there was no evidence of a relationship between age and gender and the volume of ICH. In the study by Wasay et al (10) findings showed that there was no significant relationship between age and ICH incidence, and they concluded that more than $30 \%$ of the patients referred to the hospital had high ICH, which is consistent with the results of our study. In the present study, ICH occurred in $76.92 \%$ of the patients who had hypertension for less than 10 years, and the probability of hemorrhage gradually decreased with age, so that only $23.08 \%$ of the subjects with high ICH suffered from hypertension for over 10 years. This might be due to the underestimation of hypertension, especially in the early years, and the unawareness of its complications. In addition, as the high blood pressure gets chronic and gradual degenerative changes occur in 
Table 3. Univariate logistic regression between $\mathrm{ICH}$ volume and the studied factors

\begin{tabular}{|c|c|c|c|}
\hline Variable & OR & $95 \% \mathrm{Cl}$ & $P$ value \\
\hline Age & 1.012 & $0.1 .04-984$ & 0.405 \\
\hline Gender (female) & 0.586 & $0.276-1.244$ & 0.165 \\
\hline Duration of having hypertension (over 10 years) & 2.181 & $0.822-5.788$ & 0.117 \\
\hline \multicolumn{4}{|l|}{ Treatment duration } \\
\hline Less than 5 years & 1.936 & $0.498-7.518$ & 0.340 \\
\hline Over 5 years & 1.969 & $0.487-7.954$ & 0.341 \\
\hline Non-continuous use of antihypertensive drugs & 0.878 & 0.396-1.948 & 0.750 \\
\hline Lack of regular visits to a physician & 1.756 & $0.653-4.721$ & 0.264 \\
\hline IHD & 2.395 & $1.043-5.501$ & $0.039 *$ \\
\hline Diabetes & 1.354 & $0.622-2.944$ & 0.444 \\
\hline Hyperlipoproteinemia & 0.967 & $0.385-2.429$ & 0.944 \\
\hline CVA & 2.290 & $0.864-6.071$ & 0.096 \\
\hline Chronic kidney disease & 1.223 & $0.107-13.898$ & 0.871 \\
\hline
\end{tabular}

Abbreviations: ICH, Intracerebral hemorrhage; OR, odds ratio, IHD, ischemic heart disease; CVA, cerebrovascular accident.

Table 4. Multivariate logistic regression between $\mathrm{ICH}$ volume and the studied factors

\begin{tabular}{llll}
\hline Variable & OR & $\mathbf{9 5 \%}$ Cl & P value \\
\hline Gender (female) & 0.553 & $0.249-1.230$ & 0.147 \\
Duration of having hypertension (over 10 years) & 2.015 & $0.710-5.722$ & 0.188 \\
IHD & 2.243 & $1.037-5.355$ & $0.04^{*}$ \\
CVA & 3.294 & $1.354-9.558$ & $0.028^{*}$ \\
\hline
\end{tabular}

Abbreviations: ICH, Intracerebral hemorrhage; OR, odds ratio, IHD, ischemic heart disease; CVA, cerebrovascular accident.

the vessels, and also with aging, the risk of thrombosis increases in patients and this needs treatment and control of hypertension. In a study by Nikseresht and Azin (12), it was indicated that the incidence of $\mathrm{ICH}$ in people with less than 5 years from the onset of hypertension was about $67 \%$, which is in line with our study results.

Blood pressure control is one of the main factors that has protective effects on the $\mathrm{ICH}$ volume so that the results of other studies have indicated the impact of hypertension therapeutic and control interventions on $\mathrm{ICH}$ incidence and the bleeding volume and ultimately mortality (10). On the other hand, blood pressure control with antihypertensive drugs is effectively associated with ICH incidence and mortality. Wasay et al (10) stated that increasing the number of drugs to more than 2 and poor compliance were strong and independent factors increasing hemorrhage volume. However, no evidence of a relationship between the number of drugs used and the ICH volume was found in our study.

Regarding comorbidities, the results of this study showed that IHD and CVA were associated with ICH, so that IHD and CVA are associated with an increased risk of $\mathrm{ICH}$. Studies also show the role of heart diseases in increasing the incidence of hemorrhage and stroke in people with hypertension, varying with age (15). Cardiac diseases are independent and effective risk factors for ICH incidence. Coincidence of cardiac diseases with risk factors such as alcohol consumption, smoking, and lifestyle indirectly increases the risk of ICH depending on vascular conditions. However, controlling blood and clinical parameters in these patients is effective in reducing the bleeding volume.

\section{Limitations}

One limitation of this study is the lack of follow-up (after discharge from hospital) due to the absence of an exact explanation regarding the relationship between the ICH and the mortality and morbidity caused by it. Furthermore, low sample size data and conducting the research in a single center are other limitations of the present study. Therefore, it is necessary to conduct further multicenter studies with larger sample sizes in future investigations.

\section{Conclusion}

The results of this study showed that less than $30 \%$ of the subjects had a high volume of hemorrhage, and comorbidities and cardiac events were considered as strong independent risk factors in the ICH volume, associated with a worse prognosis. However, controlling blood pressure and risk factors seems essential for preventing an increase in the volume of $\mathrm{ICH}$ and the mortality and morbidities from it. This requires screening programs and increased knowledge of physicians and patients.

\section{Authors' contributions}

This study was performed and designed by MT, MF, SRH, $\mathrm{RB}, \mathrm{NM}$, and EB. Data analysis was performed by MT, NM, and EB. Critical revision of the article was provided 
by MT, MF, SRH, HV, and EB. All authors read the final draft and accepted the final revision. Finally, based on the recommendations of the international committee of medical journal editors, all authors met the criteria of authorship.

\section{Ethical Issues}

Patients' guardians gave written consent to patients' participation and to the use of data for scientific publication. This study received Ethical approval from the Medical Ethics Committee with the code IR.MUMS. MEDICAL.REC.1397.685.

\section{Acknowledgement}

The researchers are grateful to the Vice Chancellor for Research of Mashhad University of Medical Sciences and Ghaem hospital and also all the staff who contributed to the implementation of this research. We would like to thank the Clinical Research Development Unit of Peymanieh Educational and Research and Therapeutic Center of Jahrom University of Medical Sciences for editing this manuscript.

\section{References}

1. An SJ, Kim TJ, Yoon BW. Epidemiology, risk factors, and clinical features of intracerebral hemorrhage: an update. J Stroke 2017; 19(1): 3-10. doi: 10.5853/jos.2016.00864.

2. Khealani BA, Wasay M. The burden of stroke in Pakistan. Int J Stroke 2008; 3(4): 293-6. doi: 10.1111/j.17474949.2008.00214.x.

3. Sacco RL. Pathogenesis, classification, and epidemiology of cerebrovascular disease. In: Rowland LP, eds. Merrit's Textbook of Neurology. Lea \& Febiger; 1995. p. 227.

4. Iniesta J, Corral J, González-Conejero R, Piqueras C, Vicente V. Polymorphisms of platelet adhesive receptors: do they play a role in primary intracerebral hemorrhage? Cerebrovasc Dis 2003; 15(1-2): 51-5. doi: 10.1159/000067126.

5. Ghiasian M, Daneshyar s, Asna-Ashari F, Bagheri Z. Consequences of intracranial hemorrhage and its effective factors. Journal of Mazandaran University of Medical Sciences 2019; 29(174): 42-52. [In Persian].
6. Hong KS, Bang OY, Kang DW, Yu KH, Bae HJ, Lee JS, et al. Stroke statistics in Korea: part I. Epidemiology and risk factors: a report from the Korean stroke society and clinical research center for stroke. J Stroke 2013; 15(1): 2-20. doi: 10.5853/jos.2013.15.1.2.

7. Krishnamurthi RV, Moran AE, Forouzanfar MH, Bennett DA, Mensah GA, Lawes CM, et al. The global burden of hemorrhagic stroke: a summary of findings from the GBD 2010 study. Glob Heart 2014; 9(1): 101-6. doi: 10.1016/j. gheart.2014.01.003.

8. Sia SF, Tan KS, Waran V. Primary intracerebral haemorrhage in Malaysia: in-hospital mortality and outcome in patients from a hospital based registry. Med J Malaysia 2007; 62(4): 308-12.

9. Qureshi AI, Tuhrim S, Broderick JP, Batjer HH, Hondo $\mathrm{H}$, Hanley DF. Spontaneous intracerebral hemorrhage. N Engl J Med 2001; 344(19): 1450-60. doi: 10.1056/ nejm200105103441907.

10. Wasay M, Yousuf A, Lal D, Awan S. Predictors of the intracerebral hemorrhage volume in hypertensive patients. Cerebrovasc Dis Extra 2011; 1(1): 1-5. doi: $10.1159 / 000323270$.

11. Flaherty ML, Tao H, Haverbusch M, Sekar P, Kleindorfer D, Kissela B, et al. Warfarin use leads to larger intracerebral hematomas. Neurology 2008; 71(14): 1084-9. doi: 10.1212/01.wnl.0000326895.58992.27.

12. Nikseresht A, Azin HJ. Hypertension-related primary cerebral hemorrhage in patients referring to hospitals affiliated to Shiraz University of Medical Sciences. Journal of Medical Research (JMR) 2004; 2(2): 40-7. [Persian].

13. Chen G, Ping L, Zhou S, Liu W, Liu L, Zhang D, et al. Early prediction of death in acute hypertensive intracerebral hemorrhage. Exp Ther Med 2016; 11(1): 83-8. doi: 10.3892/ etm.2015.2892.

14. Zia E, Engström G, Svensson PJ, Norrving B, PessahRasmussen H. Three-year survival and stroke recurrence rates in patients with primary intracerebral hemorrhage. Stroke 2009; 40(11): 3567-73. doi: 10.1161/ strokeaha.109.556324.

15. Arboix A, Miguel M, Císcar E, García-Eroles L, Massons J, Balcells M. Cardiovascular risk factors in patients aged 85 or older with ischemic stroke. Clin Neurol Neurosurg 2006; 108(7): 638-43. doi: 10.1016/j.clineuro.2005.10.010 